\title{
Impact of Psychological Problems and Spiritual Wellbeing on Quality of Life among Hospitalized Cancer Patients
}

\author{
Mohamed Saed Mohamed ${ }^{1}$, Mawaheb Mahmoud Zaki ${ }^{2}$ and Naglaa Fathi El-attar ${ }^{3}$ \\ (1) Registered Nurse at Ministry of Health Hosh Isa Critical Care Unit, Egypt. (2,3) Assistant \\ Professor of Psychiatric \& Mental Health Nursing Faculty of Nursing-Benha University, Egypt.
}

\begin{abstract}
Background: As the efficacy of cancer treatments has improved and the life span for cancer patients has extended, interest in patients' quality of life has increased. Assessing patients' quality of life continues to gain importance as it impacts numerous facets of oncology. Aim of study: Was to assess the impact of psychological problems and spiritual wellbeing on quality of life among hospitalized cancer patients. Research design: A descriptive research design was utilized to conduct this study. Setting: This study was conducted at clinical oncology department at Nasser Institute Subjects: A convenient sample of 100 patients with cancer. Tools for data collection: Data were collected by using the following tools: I: Socio- demographic and clinical data questionnaire: to elicit data about patient characteristics and clinical data. II: Spiritual Well-being Scale (SWBS) to assess spiritual well-being. III: Simple Quality of Life Scale (FSQOLS) to assess quality of life among patients with cancer and IV: Depression, Anxiety and Stress Scale designed to measure the emotional states of depression, anxiety and stress. Results: More than half of the studied sample has poor quality of life among illness, while one tenth of them have good quality of life. Revealed that less than half of the studied sample are suffering from severe depression ,more than three quarter of them have extremely sever anxiety and more than two thirds of them have moderate stress. Conclusion: There was significant positive correlation between spiritual wellbeing and quality of life and there was negative correlation between spiritual wellbeing and stress. Recommendations: Conducting psycho-educational program for improving the psychological status of cancer patients of all types. Coordinate between oncology center and the Department of Psychiatry in the hospital for give treatment to reduce anxiety level
\end{abstract}

Key words: Cancer patients, Quality of Life, Psychological Problems, Spiritual Wellbeing

\section{Introduction:}

Cancer is an aggressive disease that has no national, ethnic, or gender boundaries. Cancer affects the lives of men, women, and families across all continents. On the one hand, it has been a major health concern and among the top three leading causes of death in many Western and non-Western cultures and societies including the United States and North Africa. On the other hand, the medical treatment and prognosis of cancer have advanced and improved a great deal over the past several decades. These changes extended patients' lives and in many cases converted cancer from a terminal to a chronic illness in many Western and non-Western societies. This means more and more patients around the world living with and will continue to live with both the long-term physical and psychosocial distress of the illness and its treatment (Penedo, et al., 2020).

Psychological disorders have been proven to be associated with poor physiological, psychological and immune outcomes in cancer patients. However, despite 


\section{Mohamed Saed Mohamed, Mawaheb Mahmoud Zaki and Naglaa Fathi El-attar}

of many challenges of the changed selfimage/body image and the altered sexual/ urinary function, relatively little is known about psychological disorders of patients with newly diagnosed with cancer. Studies aimed to investigate the prevalence of depression, anxiety, post-traumatic stress disorder (PTSD) and the associated psychosocial factors among cancer patients (Zhang, et al., 2021).

Spiritual well-being, in a positive sense, includes the following attributes: selfawareness, coping and adjusting effectively with stress, having satisfying relationships and connectedness with others, sense of faith, sense of empowerment and confidence, and living with meaning and hope. The diagnosis of a life-threatening illness such as cancer changes people's perceptions of their lives. Cancer, in particular, is known to be a highly stressful experience associated with physical distress and emotional difficulties. A diagnosis of advanced or recurrent cancer puts patients at particular risk for psychological distress because of debilitated health, symptoms associated with disease progression, and impending death there for it affect spiritual wellbeing (Treml, et al., 2021).

Effect of cancer on Quality Of Life (QOL) may vary from person to person. One notable area of growing research interest over the past few decades is the association between spirituality and QOL. As a metaanalysis based on 48 empirical studies shows, the relationship between spirituality and QOL is stable and consistent across sample characteristics. However, a recent review of the cancer literature failed to support a definite association between spirituality and well-being, but authors pointed out the need to differentiate spirituality from spiritual wellbeing (Counted et al., 2018).

The goal of intervention is to improve and enhance quality of life at the end of life for liver cancer patients, providing a new paradigm that may effectively assist patients in terms of cancer treatment and holistic care approaches through spirituality and positive emotional coping. Also this will be directly useful for practicing nurses and clinicians to increase self-confidence by understanding the unique phenomenon of cancer experiences at the end of life. In addition to enhancing professional knowledge in the specific population under study, management of the quality of life for chronically critically ill patients who have end of life issues may be promoted through interdisciplinary collaborative research (Surbone, et al., 2018).

\section{Significance of the study}

In Egypt, Incidence rates up to 2017 were published in volumes IX and $\mathrm{X}$ of cancer incidence in five continents, date of end of registry activities due to failure of sustainability. The published crude and agestandardized incidence rates from that registry are 96.5 and 132.6/100,000 males and 97.3 and 122.1/100,000 females (Znaor, et al., 2018).

\section{Aim of study:}

The aim of the study was to assess the impact of psychological problems and spiritual wellbeing on quality of life among hospitalized cancer patients.

\section{Research questions:}

-What are the levels of psychological problems and spiritual wellbeing among hospitalized cancer patients?

-What is the impact of psychological problems and spiritual wellbeing on quality of life among hospitalized cancer patients?

\section{Subject and Methods:}

\section{Research design:}

A descriptive research design was utilized to conduct this study. 


\section{Cancer Patients}

\section{Setting:}

This study was conducted at clinical oncology department at Nasser Institute. The hospital affiliated to the Ministry of Health. It included a hospital with 850 beds. NIH was opened in July 1987. It is resides over on areas of about $(130,000$ $\mathrm{m} 2$ ). It has a main building and 3 associated buildings. The main building has 8 floors with 2 level basements. It has over about 40 medical specialties. Sample:

A convenience sample of 100 patients with cancer had been included in this study

\section{Inclusion criteria:}

- Patients diagnosed with cancer and aged from 18-65 years

- Both sexes

- Able to communicate clearly

- Agree to participate in the study

\section{Exclusion criteria:}

- Patients with another chronic physical disease

- Patients who have history of psychotic symptoms

- Patients who have history of neurological disorder

- Patient who have visual and hearing impairments

Tools for data collection: four tools were used in this study.

Tool 1: Structured interview questionnaire, it was developed by the investigator it was divided into two parts:

Part 1: Socio- demographic Data: to elicit data about patient characteristics such age, sex, marital Status, educational level.

Part 2: Clinical data: as; years of illness, numbers of hospital admission.

Tool 2: Spiritual Well-being Scale (SWBS), the original SWBS was designed by
Paloutzian \& Ellison (1985) to assess spiritual well-being. The SWBS evolved into a 20 items measuring of two dimensions of overall spiritual well-being: (a) religious wellbeing and (b) existential well-being. 10 of the items are designed to measure a person's religious well-being while the other 10 items measure existential well-being.

\section{Scoring system:}

The total scores range from 20 to 80 using a Likert-type scale from 1 (strongly disagree), 2(disagree), 3(agree) to 4 (strongly agree)

-Low spiritual well-being ranged from (2040)

-Moderate spiritual well-being ranged (41-60)

-High spiritual well-being ranged from (6180).

Tool 3: Fox Simple Quality of Life Scale (FSQOLS): It was developed by Fox (2002). It is the short version of the QOL Index (Ferrans \& Powers, 1985) to assess QOL among patients with cancer. The total items of the QLI were reduced from 32 items to 25 items.

\section{Scoring system:}

-Poor quality of life ranged (0-24)

-Moderate quality of life ranged (25-49)

-High quality of life ranged (50-75).

Tool 4: Depression, Anxiety and Stress Scale - 21 Items: It was originally developed by (Lovibond\& Lovibond, 1995) it was a set of three self-report scales designed to measure the emotional states of depression, anxiety and stress.

\begin{tabular}{|c|c|c|c|}
\hline & Depression & Anxiety & Stress \\
\hline Normal & $0-9$ & $0-7$ & $0-14$ \\
\hline Mild & $10-13$ & $8-9$ & $15-18$ \\
\hline Moderate & $14-20$ & $10-14$ & $19-25$ \\
\hline Severe & $21-27$ & $15-19$ & $26-33$ \\
\hline $\begin{array}{c}\text { Extremely } \\
\text { Severe }\end{array}$ & $28+$ & $20+$ & $34+$ \\
\hline
\end{tabular}




\section{Mohamed Saed Mohamed, Mawaheb Mahmoud Zaki and Naglaa Fathi El-attar}

\section{Content validity and Reliability:}

Arabic translation was done by researcher for tools. Content validity of tools was done by jury of 5 experts (4 in Psychiatric Nursing Field from Benha, Menufia and Ain-shams University and 1 in Psychiatric Medicine Field from Benha) who checked the relevancy, comprehensiveness, clarity and applicability of the questions. According to their opinions no modifications were done. Internal consistency of the tools was checked by test-retest reliability.

\begin{tabular}{|l||c|c||}
\hline \multicolumn{1}{|c|}{ Tool } & \multirow{2}{*}{ Items } & Reliability \\
\cline { 3 - 3 } & & Cronbach's Alpha \\
\hline \hline $\begin{array}{l}\text { Spiritual Well- } \\
\text { being Scale }\end{array}$ & 20 & 0.72 \\
\hline \hline Fox QOLScale & 25 & 0.84 \\
\hline \hline DASS & 21 & 0.79 \\
\hline
\end{tabular}

\section{Pilot study:}

Before embarking on the field work, the tools had been designed, they were tested for their clarity, feasibility and relevancy and to estimate the time needed to complete its items it was applied on $10 \%$ of sample size (10 patients) who were excluded from the final sample. According to pilot study no modification were done

\section{Ethical considerations:}

The objective and aim of the study were clarified by the researcher to every participant in the study, oral consent obtained from each patient before conducting the interview and they were assured for maintaining anonymity and confidentiality

\section{Field work:}

The researcher started data collection by introducing himself to the patients.

- Brief description about the purpose of the study and the type of questionnaire required to fill was given to each patient.
- Data collection was done by interviewing each patient individually.

-The researcher started the data collection from January to beginning of the first week of April 2021

- The researcher started data collection from 10 am to $12 \mathrm{pm}$ with interviewing patients in their rooms, two days per week.

- The interview lasted from 20-30 minutes with each patient depending on the response of them. The researcher collected data from 4 patients per day which equally 32 patients per month.

\section{Statistical analysis :}

The collected data was organized, tabulated and statistically analyzed using the statistical package of social studies (spss) version 22.0.qualitative data were described using number and percent. Quantitative data were described mean percent score. Significance of the obtained results was judged at the 5\%level. Finally analysis and interpretation of data were conducted. P-value of 0.05 or less were co

\section{The following tests were done:}

\section{$\square$ Chi-square (X2) \\ $\square$ Probability (P-value) \\ $\square$ Correlation (r) \\ Results:}

Table (1) Shows that the mean age of the studied sample is \pm 49.65 years old.as for marital status, it reveals that less than half of them $(47 \%)$ are married, more than half of them $(58 \%)$ are female. Regards educational level, more than one third of them are illiterate and worker $(33 \%, 35 \%)$ respectively.

Table (2) Clarifies that more than three quarters $(78 \%)$ of the studied sample are suffering from illness from 1-5 years admitted to hospital from 6-10 times.as for received treatment more than two third $(63.0 \%)$ of them are receiving radiotherapy treatment and less than half $(43 \%)$ of them are diagnosed hepatic cancer. 


\section{Cancer Patients}

Figure (1) Illustrates that more than two third $(64.0 \%)$ of the studied sample have low spiritual wellbeing, while one quarter of them $(25 \%)$ have moderate spiritual wellbeing.

Figure (2) Clarifies that more than half $(64 \%)$ of the studied sample has poor quality of life among illness. While one tenth $(11 \%)$ of them has good quality of life.

Figure (3) Reveals that less than half (46\%) of the studied sample are suffering from severe depression, more than three quarter $(77 \%)$ of them have extremely sever anxiety and more than two thirds (71\%) of them have moderate stress.

Table (3) Reveals that there significant positive correlation between spiritual wellbeing and quality of life and there was negative correlation between spiritual wellbeing and stress. Adding to that there was positive correlation between stress $\&$ anxiety and depression. Lastly, there was significant positive correlation between anxiety and depression.

Table (1): Percentage distribution of sociodemographic characteristics of the studied patients $\mathrm{N}=\mathbf{1 0 0}$.

\begin{tabular}{|c|c|c|}
\hline$\overline{\text { Socio demographic }}$ & $\overline{\overline{\text { Number }}}$ & $\overline{\overline{\%}}$ \\
\hline \multicolumn{3}{|l|}{ Age } \\
\hline $18<33$ years & 15 & 15.0 \\
\hline $33<48$ vears & 18 & 18.0 \\
\hline $48<65$ & 67 & 670 \\
\hline Mean \pm SD & \multicolumn{2}{|l|}{$49.65 \pm 10.94$} \\
\hline \multicolumn{3}{|l|}{ Sex } \\
\hline Male & 41 & 41.0 \\
\hline Female & 59 & 59.0 \\
\hline \multicolumn{3}{|l|}{ Marital Status } \\
\hline Single & 26 & 26.0 \\
\hline Married & 47 & 47.0 \\
\hline Divorced & 16 & 160 \\
\hline Widowed & 11 & 11.0 \\
\hline \multicolumn{3}{|l|}{ Educational level } \\
\hline Illiterate & 33 & 33.0 \\
\hline Basic education & 25 & 25.0 \\
\hline Secondary & 21 & 21.0 \\
\hline University & 18 & 18.0 \\
\hline Post graduated & 3 & 3.0 \\
\hline \multicolumn{3}{|l|}{ Occupational status } \\
\hline Student & 12 & 12.0 \\
\hline Doesn't work & 33 & 33.0 \\
\hline Worker & 35 & 35.0 \\
\hline Free work & 20 & 20.0 \\
\hline \multicolumn{3}{|l|}{ Residence } \\
\hline Rural & 36 & 36.0 \\
\hline Urban & 64 & 64.0 \\
\hline \multicolumn{3}{|l|}{ Number of siblings } \\
\hline One & 25 & 25.0 \\
\hline Two & 50 & 50.0 \\
\hline Three & 25 & 25.0 \\
\hline \multicolumn{3}{|l|}{ Income } \\
\hline Enough & 56 & 56.0 \\
\hline Not enough & 44 & 44.0 \\
\hline
\end{tabular}


Mohamed Saed Mohamed, Mawaheb Mahmoud Zaki and Naglaa Fathi El-attar

Table (2): Percentage distribution of Clinical data characteristics of the studied patients $\mathrm{N}=\mathbf{1 0 0}$.

\begin{tabular}{|c|c|c|}
\hline$\overline{\text { Clinical data }}$ & $\overline{\text { Number }}$ & $\overline{\%}$ \\
\hline \multicolumn{2}{|l|}{ Onset of illness } & \\
\hline Less than 1 Year & 17 & 17.0 \\
\hline $1<5$ years & 78 & 78.0 \\
\hline $5 \leq 10$ years & 5 & 5.0 \\
\hline Mean \pm SD & $3.10 \pm 1.9$ & \\
\hline \multicolumn{2}{|l|}{ Numbers of admission } & \\
\hline $1-5$ times & 78 & 78.0 \\
\hline 6-10 times & 22 & 22.0 \\
\hline Mean \pm SD & $3.6 \pm 2.5$ & \\
\hline \multicolumn{2}{|l|}{ Received treatment } & \\
\hline Chemotherapy & 14 & 14.0 \\
\hline Radiotherapy & 63 & 63.0 \\
\hline Surgical & 23 & 23.0 \\
\hline \multicolumn{2}{|l|}{ Diagnosis } & \\
\hline Brain cancer & 20 & 20.0 \\
\hline Hepatic cancer & 43 & 43.0 \\
\hline Breast cancer & 25 & 25.0 \\
\hline Others (colon, prostate, and lung) & 12 & 12.0 \\
\hline
\end{tabular}

\section{Spititual Wellbeing}

\section{$11 \%$}




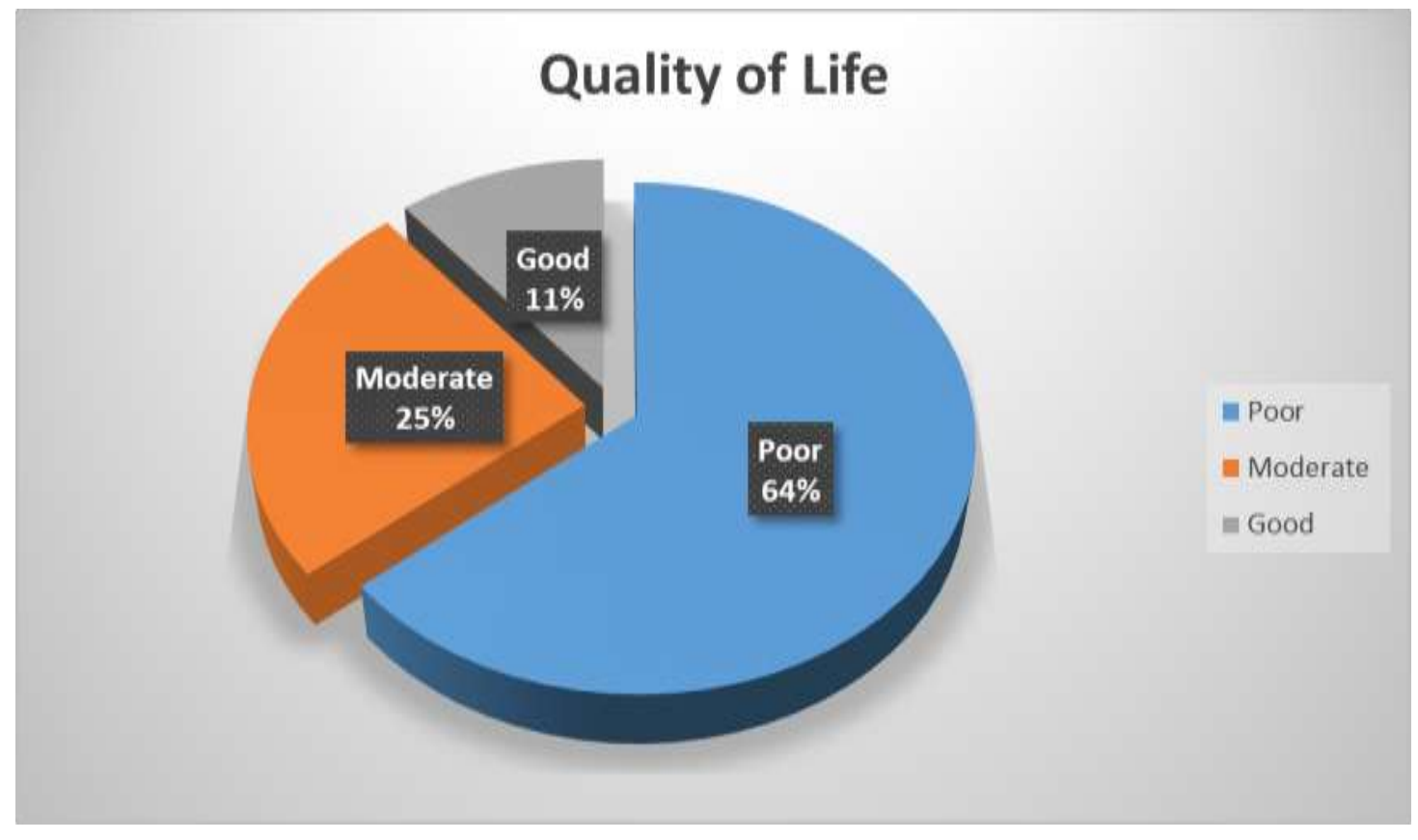

Figure (2) Total quality-of-life level among studied patients

\section{Depression, Anxiety and Stress (DASS-21)}

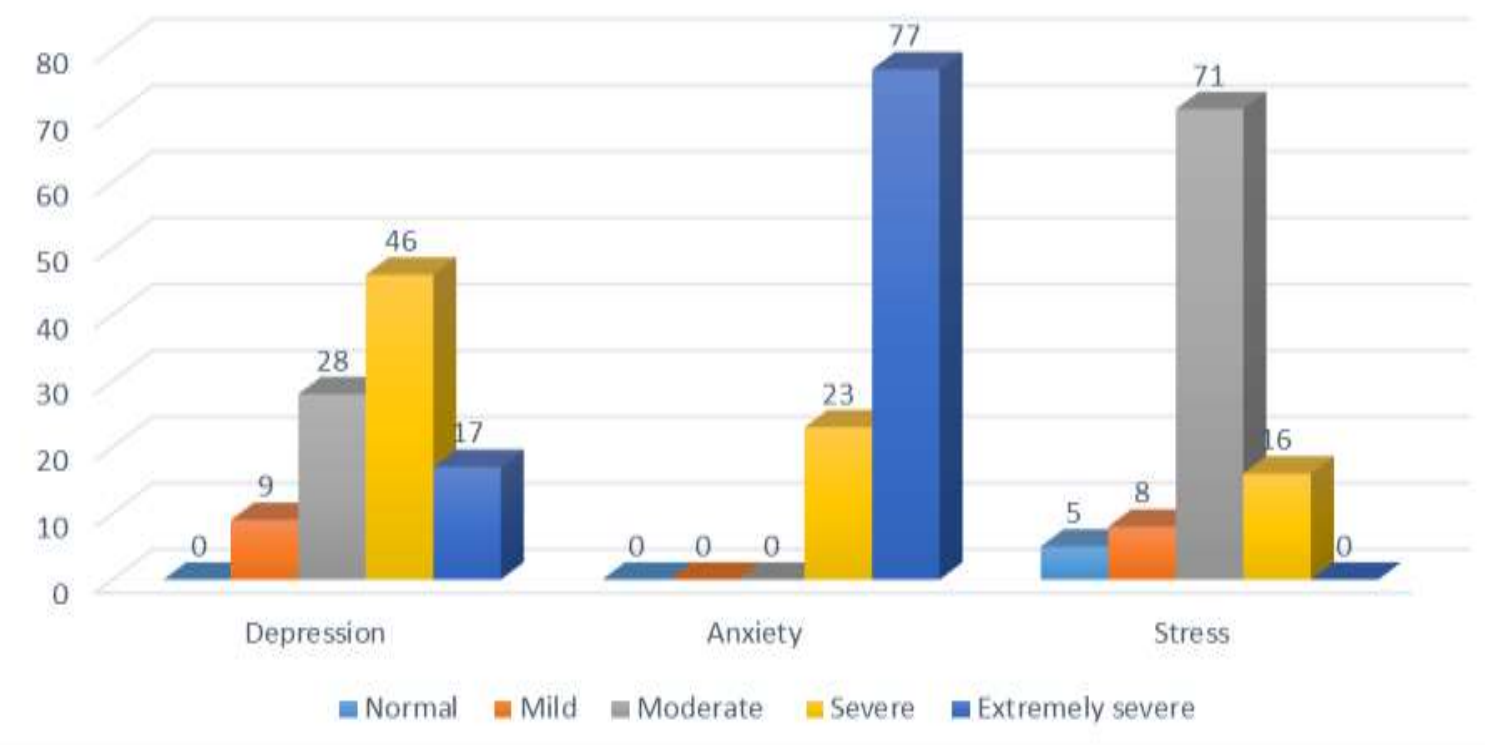

Figure (3) Total levels of depression, anxiety and stress among studied patients. 
Table (3) Correlation between spiritual wellbeing, quality of life, depression, stress and anxiety $N=100$

\begin{tabular}{|c|c|c|c|c|c|}
\hline \multicolumn{2}{|l|}{ Items } & \multirow{2}{*}{$\begin{array}{l}\text { Spiritual } \\
\text { wellbeing }\end{array}$} & \multirow{2}{*}{$\begin{array}{l}\text { Quality of } \\
\text { life }\end{array}$} & \multirow[t]{2}{*}{ Stress } & \multirow[t]{2}{*}{ Anxiety } \\
\hline \multirow{2}{*}{$\begin{array}{l}\text { spiritual } \\
\text { wellbeing }\end{array}$} & $\overline{\mathbf{R}}$ & & & & \\
\hline & P Value & & & & \\
\hline \multirow{2}{*}{$\begin{array}{l}\text { quality of } \\
\text { life }\end{array}$} & $\overline{\mathbf{R}}$ & $0.30 * *$ & & & \\
\hline & P Value & 0.002 & & & \\
\hline \multirow[t]{2}{*}{$\overline{\text { Stress }}$} & $\mathbf{R}$ & $-0.41 * *$ & -0.005 & & \\
\hline & P Value & $\overline{0.000}$ & 0.96 & & \\
\hline \multirow[t]{2}{*}{ Anxiety } & $\overline{\mathbf{R}}$ & -0.12 & -0.01 & $0.59 * *$ & \\
\hline & P Value & 0.21 & 0.89 & 0.000 & \\
\hline \multirow[t]{2}{*}{ Depression } & $\overline{\mathbf{R}}$ & -0.08 & -0.05 & $0.41 * *$ & $0.26^{* * *}$ \\
\hline & P Value & 0.40 & 0.60 & 0.000 & 0.007 \\
\hline
\end{tabular}

\section{Discussion:}

Living with an illness such as cancer presents with multiple life challenges and opportunities. Amidst the more notable changes in physical, emotional and social well-being comes an inevitable impact of the disease on existential and spiritual notions of life's meaning and greater purpose.

This study reported that mean age of the studied sample is $(49.65 \pm 10.94)$ years old as for marital status, it revealed that less than half of them were married, more than half of them were female. Regarded educational level, more than one third of them were illiterate and worker respectively. Clinical data of study showed that more than three quarters of the studied sample were suffering from illness from (1-5) years admitted to hospital from (6-10) times. As for received treatment more than two third of them were receiving radiotherapy treatment and less than half of them were diagnosed hepatic cancer.

The study showed that more than two third of the studied sample have low spiritual wellbeing, while one quarter of them have moderate spiritual wellbeing. This result may be due to that all patients included in sample are Muslims and the good relation with god.

These results were consistent with study done by Martins et al., (2020), who reported that more than half of participants level of SWB, one quarter are good, less than quarter are mediocre, and a few number are excellent.

$$
\text { In contrast with this study }
$$

Dubourdieu\& Escudero (2021), reported that cancer patients felt satisfied with current physical and spiritual wellbeing. Participants expressed general gratitude that they were 
able to rebound from the physical side effects from cancer and its treatments, and felt general gratitude or pride in their improved health.

As for distribution for quality of life among studied patients, the study reported that more than two third of the studied sample report quality of life is important to them, they have support from friends, while more than half of them doesn't have sense of wellbeing and clarified that more than half of the studied sample have poor quality of life among illness. While one tenth of them have good quality of life. According to researcher view, this result may be due to the physical and emotional effects of cancer treatment, hospitalization and charged living with cancer.

The results were consistent with study of, Nayak et al., (2017), who reported that most of cancer patients were in the below average category of QOL score and the QOL of the cancer patients was influenced by reported symptoms. On the contrary results of study done by $\mathbf{H u}$ et al., (2018) who reported that subjects rated their quality of life as high on a scale from one to 100 , the mean quality of life rating was 65 with a standard deviation of 27.

Regarding total levels of depression, anxiety and stress among studied patients the current study's result demonstrated that less than half of the studied sample are suffering from severe depression, more than three quarter of them have extremely severe anxiety and more than two thirds of them have moderate stress. Receiving a diagnosis or treatment for cancer is a significant distressing occasion for most patients.

These results were in the same line with Guest et al., (2018) the results of the DASS 21 indicate increase on the participants' depression, anxiety and stress scores. And similar to the study done by Sharma\& Zhang, (2017) that reported that near half of cancer respondents reported moderate to severe depression, more than one quarter of them had moderate anxiety to potential cause of concern and more than three quarter of them had moderate to high perceived stress.

Regarding correlation between spiritual wellbeing, quality of life, depression, stress and anxiety these study results revealed that there significant positive correlation between spiritual wellbeing and quality of life and there was negative correlation between spiritual wellbeing and stress. Adding to that there were positive correlation between stress $\&$ anxiety and depression. Lastly, there was significant positive correlation between anxiety and depression. The present results confirmed the association between spirituality and correlation between spiritual wellbeing, quality of life, depression, stress and anxiety. Healthcare providers should consider the spiritual well-being of patients with cancer who have low quality of life or severe symptoms.

This result were consistent with study done by Philipp et al., (2021), that demonstrated that perceived distress among the cancer patients was significantly associated with anxiety but not depression. This finding was reflected at each point of the study at baseline, 6 months and 12 months; where patients who were moderate to severely distress scored higher in the anxiety scale. There was no difference in the depression scores regardless of the distress level of the cancer patients. The association was further shown in the positive correlation between the changes of distress with the changes of anxiety scores. Over the 12 months period, 


\section{Mohamed Saed Mohamed, Mawaheb Mahmoud Zaki and Naglaa Fathi El-attar}

the reduction of distress was associated with the reduction of anxiety.

In contrast Mundle et al., (2021), reported that reduction of distress had no association with the changes in the depression scores. Study group Utilizing the two predictors (depressive symptoms and spiritual well-being) on QOL in primary cancer patients, the hierarchical regression model revealed that spiritual well-being was statistically significant and the greatest predictor of QOL when controlling duration of the illness. When controlling duration of the illness, the second greatest predictor of QOL was depressive symptoms but the contribution made by depressive symptoms was not statistically significant.

\section{Conclusion:}

More than two third of the studied sample have low spiritual wellbeing, while one quarter of them have moderate spiritual wellbeing. More than half of the studied sample has poor quality of life among illness. While one tenth of them have good quality of life. Also the results demonstrated that less than half of the studied sample are suffering from severe depression, more than three quarter of them have extremely sever anxiety and more than two thirds of them have moderate stress. There are statistically significant differences between spiritually wellbeing and quality of life, stress. There significant positive correlation between spiritual wellbeing and quality of life and there was negative correlation between spiritual wellbeing and stress. Adding to that there was positive correlation between stress $\&$ anxiety and depression. Lastly, there was significant positive correlation between anxiety and depression.

\section{Recommendations:}

- Conducting psycho-educational program for improving the psychological status of cancer patients of all types.

- Coordinate between oncology center and the Department of Psychiatry in the hospital for give treatment to reduce anxiety level

- Conducting psychological and spiritual wellbeing counseling program for the patients with cancer.

\section{References:}

Counted, V., Possamai, A., \& Meade, T. (2018). Relational spirituality and quality of life 2007 to 2017: An integrative research review. Health and quality of life outcomes, 16(1), 1-18.

Dubourdieu, M., \& Escudero, C. (2021). Caring for those Who Care Biopsychoeducation for Health Care Personnel from Psychoneurotic-immuno-endocrinology (PNIE) and Integrative Psychotherapy PNIE (PI PNIE). EC Nursing and Healthcare, 3, 150-167.

Ferrans, C., \& Powers, M. (1985). Quality of life index: development and psychometric properties. Advances in nursing science.

Fox, E. (2002). Attentional bias for threat: Evidence for delayed disengagement from emotional faces. Cognition \& emotion, 16(3), 355-379.

Guest, R., Tran, Y., Gopinath, B., Cameron, I. D., \& Craig, A. (2018). Prevalence and psychometric screening for the detection of major depressive disorder and post-traumatic stress disorder in adults injured in a motor vehicle crash who are engaged in compensation. BMC psychology, 6(1), 1-12.

Hu, Y., Ma, Z., Zhang, H., Gao, T., Gao, J., Kong, Y., \& Mei, S. (2018). Prevalence of 


\section{Cancer Patients}

and factors related to anxiety and depression symptoms among married patients with gynecological malignancies in China. Asian journal of psychiatry, 37, 90-95.

Lovibond, P., \& Lovibond, S. (1995). The structure of negative emotional states: Comparison of the Depression Anxiety Stress Scales (DASS) with the Beck Depression and Anxiety Inventories. Behaviour research and therapy, 33(3), 335-343.

Martins, H., Dias Domingues, T., \& Caldeira, S. (2020). Spiritual well-being in cancer patients undergoing chemotherapy in an outpatient setting: A cross-sectional study. Journal of Holistic Nursing, 38(1), 6877.

Mundle, R., Afenya, E., \& Agarwal, N. (2021). The effectiveness of psychological intervention for depression, anxiety, and distress in prostate cancer: a systematic review of literature. Prostate Cancer and Prostatic Diseases, 1-14.

Nayak, M., George, A., Vidyasagar, M., Mathew, S., Nayak, S., Nayak, B., \& Kamath, A. (2017). Quality of life among cancer patients. Indian journal of palliative care, 23(4), 445

Paloutzian, R., \& Ellison, C. (1985). Norms for the spiritual weil-being scale. Journal of psychology and theology, 19(1), 56-70.

Penedo, F., Oswald, L., Kronenfeld, J., Garcia, S., Cella, D., \& Yanez, B. (2020). The increasing value of eHealth in the delivery of patient-centred cancer care. The Lancet Oncology, 21(5), e240-e251.

Philipp, R., Mehnert-Theuerkauf, A., Koranyi, S., Härter, M., \& Vehling, S. (2021). The role of attachment avoidance: A longitudinal mediation model predicting existential distress in patients with advanced cancer. Psycho-Oncology

Sharma, A., \& Zhang, J. (2017). Predictors of post traumatic growth among breast cancer patients in Nepal. Asian Pacific Journal of Health Sciences, 4(2), 9-17.

Surbone, A., Goldzweig, G., \& Baider, L. (2018). Psychosocial and Spiritual Issues in Supportive Cancer Care. In The MASCC Textbook of Cancer Supportive Care and Survivorship (pp. 665-680).

Treml, J., Schmidt, V., Nagl, M., \& Kersting, A. (2021). Pre-loss grief and preparedness for death among caregivers of terminally ill cancer patients: A systematic review. Social Science \& Medicine, 114240.

Zhang, Y., Cui, C., Wang, L., Yu, X., Wang, Y., \& Wang, X. (2021). The Mediating Role of Hope in the Relationship between Perceived Stress and Post-Traumatic Stress Disorder among Chinese Patients with Oral Cancer: A Cross-Sectional Study. Cancer Management and Research, 13, 393.

Znaor, A., Eser, S., Anton-Culver, H., Fadhil, I., Ryzhov, A., Silverman, B., \& Bray, F. (2018). Cancer surveillance in northern Africa, and central and western Asia: challenges and strategies in support of developing cancer registries. The Lancet Oncology, 19(2), e85-e92. 
تأثير المشاكل النفسية والرفاهية الروحية على جودة الحياة بين مرضى السرطان في المستثفيات محمد سعيد محم - مو اهب محمود زكي - نجلاء فتحي العطار

مع تحسن فعالية علاج السرطان وإطالة العمر الافتراضي لمرضى السرطان ، ازداد الاهتمام بجودة حياة المرضى. و لا يز ال تقييم جودة حياة المرضى يكتسب أهمية لأنه يؤثر على العديد من جوانب العب علم الأورام.

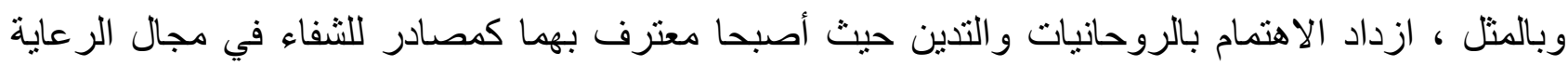

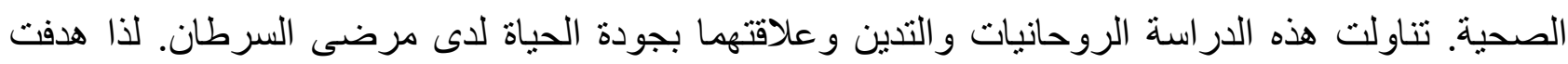

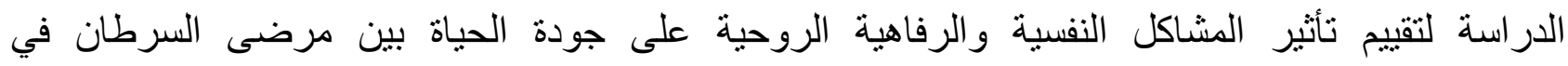

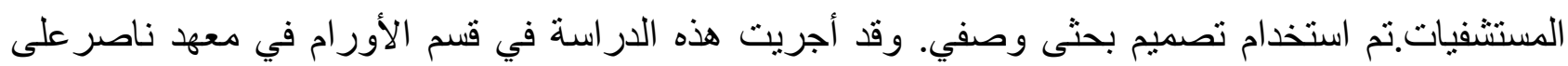

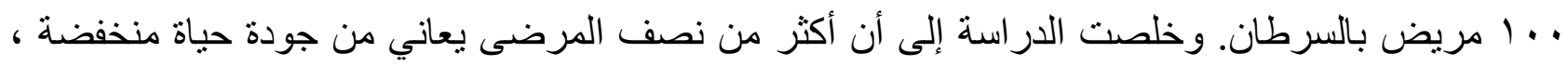
بينما يتمتع عُشر هم بنو عية حياة جيدة. وكثف أن أقل من نصف المرضى يعانون من اكتئاب حاد ، وأكثر من

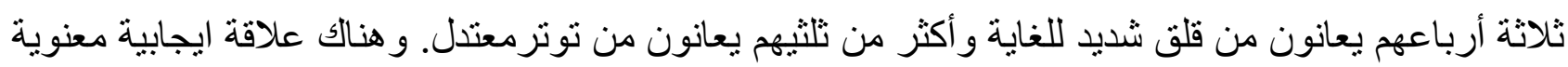

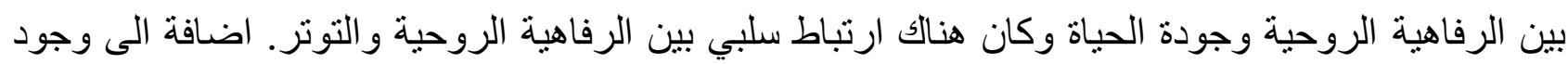

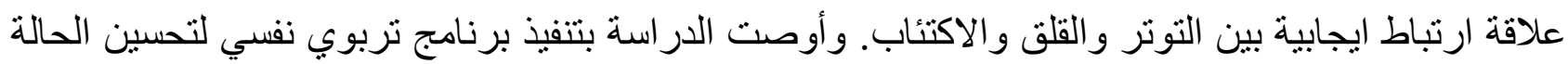
النفسية لمرضى السرطان بأنواعه و التنسيق بين مركز الأورام وقسم الطب النفسي في المستشفى لتقديم العلاج لتقليل مستوى القلق. 